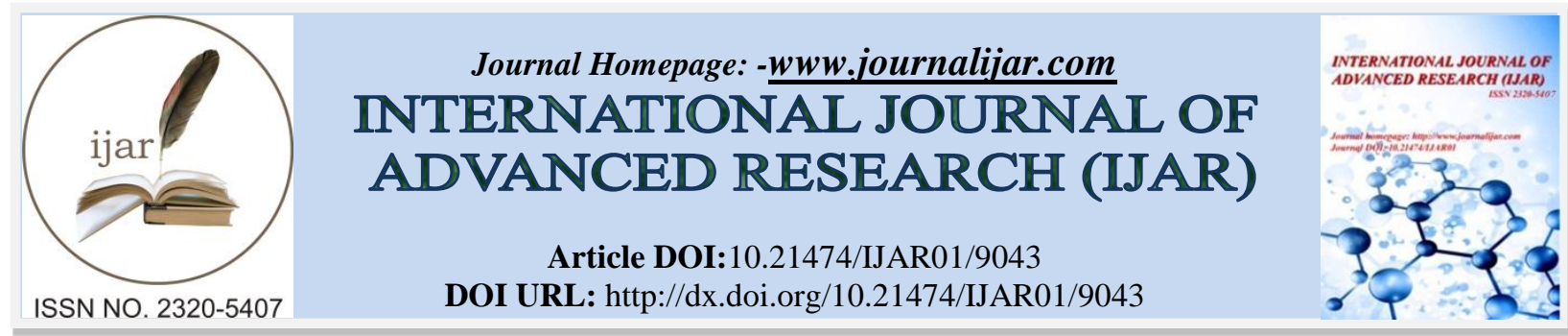

RESEARCH ARTICLE

\title{
INTERACTIVE LEARNING AND LINGUISTIC ENVIRONMENT: COPING WITH THE CHALLENGES OF INTERCULTURAL COMMUNICATION OF SUDANESE AND ETHIOPIAN STUDENTS.
}

Caezar D. Pamin.

Faculty, Laguna State Polytechnic University Santa Cruz, Laguna College of Teacher Education.

\section{Manuscript Info}

Manuscript History

Received: 10 March 2019

Final Accepted: 12 April 2019

Published: May 2019

\section{Abstract}

The need to become language proficient is in demand. Non-native speakers seek competent individuals who are confident in expressing themselves in the second language. Hence, the assurance of producing language proficient learner is still far at hand because of the limited interaction and the lack of confidence and competence in using English language.

The present study aimed to find out the influence of interactive learning and linguistic environment in oral English language performance of college students in Sudan and Ethiopia. (Madrunio et. al.,) said that it has become a widespread notion that speakers' use of different language results in intercultural communication. It is thus important to emphasize that the ownership of English cannot be attributed to just one country or to those who use it as a native or home language. The varieties of English spoken by different speech communities have evolved for a reason. They use it for communal purposes. These varieties have been heavily influenced by the local culture and its speakers.

Specifically, this study sought to answer the following questions: 1 . What is the mean level of interactive learning through the following: oral presentations, dialogues, small group activity, role playing; 2. What is the mean level of the following components of linguistic environment peers, exposure to language and exposure to print materials; 3. What is the mean level of the students' performance in oral English language in terms of vocabulary, grammar, pronunciation, grade in English; and 4. Do interactive learning and linguistic environment singly or in combination have significant effect on the oral English language performance of college students in Sudan and Ethiopia?

The number of respondents was determined thru stratified random sampling and with the use of Regression Analysis the result was made. One hundred fifty students and ten teachers of English were utilized in this study. Weighted mean was used to get the mean level of the respondents' competencies, mean and standard deviation for the students' performance in English.

The overall mean level of pupils' interactive learning through oral presentations, dialogue, small group activity and role playing were $3.78,3.75,3.95$, and 3.86 respectively. The figures suggest "high 
extent" off engagement in such activities. The students' linguistic environment such as peers, and exposure to language and exposure to print materials garnered means of 2.59 , and 2.54 respectively verbally interpreted to have "moderate extent".

The students' performance in oral English language in terms of vocabulary, grammar, and pronunciation obtained the mean scores of $3.28,3.26$ and 3.35 respectively, which were all interpreted as "moderate extent". In general, their performance in English language in terms of grade was "needs improvement" as recorded by 83.05 mean.

The interactive learning activities and linguistic environment recorded significant relationship on English language performance in terms of vocabulary, grammar, pronunciation. Grade appeared to have significant relationship with some learning activities like oral presentations and dialogue.

Inasmuch as interactive learning and linguistic environment registered significant relationship to the pupils' performance in oral English language; hence in this study the hypothesis stating that there is no significant relation between interactive learning and linguistic environment was completely rejected.

It is recommended that teachers continue to use the interactive learning activities in the classroom to encourage the students to use the English language. Home (family) as part of the students' linguistic environment and considered a big factor that influence their oral English language performance, the available materials needed for their development should be provided.

Copy Right, IJAR, 2019, All rights reserved.

\section{Introduction:-}

Teachers who are teaching in English to non-native speakers with varied cultural backgrounds find it hard to measure performance in English because they can hardly express themselves using the language. It is difficult to extract information from someone who has no idea at all, unlike if they mingle with each other whom they are with, they will be able to come up with ideas they never imagined they have.

In Africa where English is receiving such a great importance in paving the road through global competence. English is a subject that everybody is passing up, thus manifesting low English language performance.

English language requires practice and repeated drill even at the start of child's school years. It is understandable that a person can hardly master the language most especially if he does not grow in an English-speaking community. Many philosophers attested that spoken language is much easier to acquire than that of the language taught in most disciplines. Hence, educators worldwide tried every potential approach that might cater the students' needs in order to achieve a much higher motivation and interest in acquiring and learning English. Pursuing the language to be learned is quite difficult because of the various factors affecting the students' interest of learning such as environment, culture, family, peer and religion. Thus, achieving the motivated students in learning English seem stiff and a hard task.

Passive learning still has its place; however, schools have to embrace interactive learning environment in order to inspire students to participate in conversation, role-playing group exercises in class and develop an analytic reasoning through group collaboration. Students who engage themselves in team-based activities sharpens critical thinking skills they also learn how to make decisions by exploring in an open-ended question with imagination and logic.

Schools have to embrace learning environment in order to inspire students to participate in conversation and develop analytic reasoning through group collaboration. Hence, some students are not adept to conversational English. At home, parents should not simply ask their children how their day to get the expected answer. Instead they should 
think of questions that will spur a conversation. Adequate supplies of reading materials will also help the students to expose themselves in interacting with others because the more they are exposed to information the more they are confident to socialize and share their thoughts. In school, teachers should engage students in group activities that will enhance the ability of the student to think critically and speaking activities that will inspire them to interact with their peers.

(Thoma, 2015) The use of English urge Ethiopians to improve their methods of teaching it, others contend that the exclusive use of English after primary education is a threat to Ethiopian identity and supports outdated prejudices about the supposed inferiority of African languages.

On the level of the state, there are also reasons why one might want Ethiopia to speak English or, on the other hand, why Amharic might be better. Mastery of what is arguably today's most important international language could improve business prospects and help the country to be more economically competitive on a global level. In the end, though, it might depend on just what path one wants the nation to take.

(Elema, 2015) agrees about the importance of outside practice, and says that this is also a problem for adult learners. Some of his students mention wanting to improve English to travel abroad or to help younger siblings who are studying the language, but many also refer to the need to find work.

(Mohammed 2015) English language graduates in Sudan where Arabic is the native language find it difficult in using English for communication. When engaged in authentic communication situations, they often lack some of the vocabulary or language items they need to get their meaning across. As a result, they cannot keep the interaction going for an extended period of time. These graduates when they join the Ministry of Education as teachers of English will definitely have very little to offer. This is really a very serious problem. This is not an impressionistic point of view.

Another type of improving English is the intercultural communication. (Madrunio et. al. 2018) mentioned that it is between or among people having different linguistic, religious, ethnic, social, and professional backgrounds.

\section{Objectives:}

The purpose of this study was to determine the influence of interactive learning and linguistic environment in oral English language performance of Sudanese and Ethiopian students in the African region.

Specifically, the study sought to answer the following questions:

1. What is the mean level of the students' interactive learning activities through:

1.1 Oral presentations

1.2 Dialogues

1.3 Small-group activity

1.4 Role playing

2. What is the mean level of the following components of linguistic environment as to:

2.1 peers

2.2 exposure to language

2.3 exposure to print materials

3. What is the mean level of Intercultural Communication in terms of:

3.1 vocabulary

3.2 grammar

3.3 pronunciation

4. Do interactive learning and linguistic environment singly or in combination have significant effect in oral English language performance of Sudanese and Ethiopians in the African region. 


\section{Methodology:}

This study is quantitative in nature. It uses the descriptive research to present valuable information in realizing the nature of the study. It does not only make use of the acquired facts of the existing conditions but also helps distinguish the significant connection between the current phenomena. It was conducted to college students in Khartoum and Addis Ababa. It was limited to 150 students studying in both University in School Year 2018-2019.

Stratified sampling was used in this study since the method involves the division of a population into smaller groups known as strata. In stratified random sampling the strata are formed based on members' shared attributes or characteristics. A random sample from each stratum was taken in a number proportional to the stratum's size when compared to the population. These subsets of the strata were then pooled to form a random sample.

\section{Literature review:}

Spoken English is the more natural and widespread mode of transmission, though ironically the one which most people find much less familiar presumably because it is so much more difficult to see what is happening in speech than in writing. However, communicative competence is very important, it is the ability not only to apply grammatical rules to form grammatically correct sentences but also to know when and where to use these sentences and to whom, Richards (2001). Nonetheless, Chomsky defined Performance as the ability of language user to apply the theory that is produce and understand an infinite number of utterances and the ability of the speaker to pass judgement on the grammaticality of sentences, on ambiguity, and paraphrases. In other words, performance is the application of the theory. "Linguistic performance and its products are in fact complex phenomena. The nature and characteristics of a particular instance of linguistic performance and its product(s) are, in reality, determined by a combination of factors: Some of the factors which influence linguistic performance are: (a) the linguistic competence or unconscious linguistic knowledge of the speaker-hearer, (b) the nature and limitations of the speakerhearer's speech production and speech perception mechanisms, (c) the nature and limitations of the speaker-hearer's memory, concentration, attention and other mental capacities, (d) the social environment and status of the speakerhearer, (e) the dialectal environment of the speaker-hearer, (f) the idiolect and individual style of speaking of the speaker-hearer, (g) the speaker-hearer's factual knowledge and view of the world in which he lives, (h) the speakerhearer's state of health, his emotional state and other similar incidental circumstances.

In practice, the language performance that we actually produce is limited by these factors. Furthermore, the sentences we actually produce often use the simpler grammatical constructions. Our speech is full of false starts, hesitations, speech errors, and corrections. The actual ways in which we produce and understand sentences are also in the domain of performance.

The degree of learning that students acquire in school has a relation to his/her academic performance. As cited by Collier (2001), language is more than just the sum of discrete parts (pronunciation, grammar, vocabulary). It is developed within culture for the purpose of conveying the beliefs and customs of that culture. He said that language usage is dynamic and contextually based (varies depends on the situation, status of the speakers and the topic), the discursive requires connected speech and requires the use of integrative skills to achieve communicative competence.

According to Qian (2008), having a larger vocabulary gives the learner a larger database from which to guess the meaning of the unknown words or behavior of newly learned words, having deeper vocabulary knowledge will very likely improve the results of the guessing work.

One commonality among everyone in the whole world is that they learned to speak before they learned grammar. Speaking is the first step for any English learner. So, if you are a novice at English, please focus on your speaking and listening skills prior to studying grammar. After being able to speak English fluently, you will realize how much easier grammar is. But it does not work the other way around. Being fluent in English speaking will help you with your grammar studies, but studying grammar studies, but studying grammar will not help you with your speaking. Krashens's theory of Second Language Acquisition states that language acquisition does not require extensive use of conscious grammatical rules and does not require tedious drill.

Acquisition requires meaningful interactions in the target-language natural communication in which speakers are concerned not with the form of their utterances but with the messages they are conveying and understanding. In obtaining English fluency studying grammar can slow your progress down significantly. Basic grammar is a 
necessity, but focusing on grammar will prevent you from being able to speak English fluently in a reasonable time frame. Grammar is most effective to improve communication and writing skills, but this only pertains to those who have a solid foundation in English fluency. Swan (2005) believed that knowing how to build and use certain structures makes it feasible to communicate common types successfully. Without these structures, it is difficult to make comprehensible sentences. He stated that in some social contexts, serious deviance from native speakers' rules can put off integration and arouse prejudice - a person who speaks badly maybe considered uneducated or stupid. This implies that learners should understand English language structures accurately to become fluent. Zhong-guo, LI and SONG Min-yan (2007) state that learners must be competent in language. The language competence means that one has a good knowledge of grammar and words, he or she can speak, read and write in grammatical foreign language. In conversation it is become crucial, if mistakes were made in one's pronunciation, grammar or words spelling, it will lead to misunderstanding and boredom to others, and even damage their relationship. If we only understand what others say partially and superficially, the communication of ideas can't be properly realized.

In Oxford International Encyclopedia (2003), grammar is presented in terms of two particular approaches 'functionalism' and 'formalism' or functional (cognitive and social perspectives) and formal grammars. In one way or another grammar can be defined in many ways and to mean different thing. Byram (2002) views grammars not only technically as a system that studies the features of language but also socially, pedagogically and linguistically. It can be said that English grammar is the set of rules within the English language itself. It has indispensable role in communication though in recent days however its role is changing especially in language teaching. Language teaching now do not too structure oriented, which is teach language through the structure built it. Michell (1996) claims that the main aims of studying grammar by linguist were not only linguistics ones, there are also social and pedagogical aims as he stated. It is clear that his claim is similar to Byram's definition $\mathrm{f}$ grammar who has been mentioned earlier, has introduced grammar from three angles: linguistic, social and pedagogical.

These views of Byram and Mitchell give confidence to the leaners who wish to speak the English language yet apprehensive that they might commit mistakes in doing so.

A theory which has had a great impact on teacher English pronunciation recently is Jenkin's Lingua Franca Core. Using conversations in English between (NNSs) Non- Native Speaker as data, Jenkins (2000) found that the chief issue for intelligibly in international contexts was pronunciation. In her proposal for a Lingua franca core (LFC) Jennifer Jenkins (2000) seeks to redefine and re-classify pronunciation error, and in so doing to embrace the sociolinguistic facts of regional variation. The proposal recognizes the rights of non-native speakers to their own legitimate regional accents rather than regarding deviation from NS pronunciation norms as error. However, Walker (2001) comments, it should not be assumed that the NS is necessarily best equipped to teach pronunciation, the best instructor is the person with a detailed practical knowledge of both the L1 and L2 phonetics

When talking about pronunciation in language, pronunciation and perception of different sounds of a language and their meaning in different contexts of language use should be considered. Pronunciation plays a vital role in personal and social lives, identities, individualities and memberships in a certain community. Often learner's pronunciation is responsible for the intelligibility. (Seidlhofer, 2002) Moreover, he said that effective teaching of pronunciation requires at least three kinds of competence of teachers: linguistic proficiency in the target language, knowledge about this language and the ability to identify and select specific aspects of language and combine them for presentation and practice in ways which are effective for learning. Teachers need to be good models and good instructors for the correct pronunciation of the target language.

Children learn better when they do it with other children of their age and by interaction with other children of their age and by interaction with people who understand their manner of expressions.

Interactive learning is an educational approach to teaching and learning that involves group of students working together to solve a problem, complete a task, or create a product. It is through the talk that learning occurs. "Collaborative Learning" (Sharec 2011) is a style of education that gets student actively participating in the classroom. This method of educating is appropriate at all age level and for all subjects. Collaborative learning brings students together to engage in team-building activities.

Interactive learning can be a better method of child education because it encourages student to work together to work together rather than compete against one another. It also presents a more social aspect to learning and a social 
environment that can help encourage a child's education. Collaborative learning is a very formal way of structuring activities in a learning environment that includes specific elements intended to increase the potential for rich and deep learning by the participants.

Dicdican (2007) said that interactive learning, teachers act as facilitators for incorporating and encouraging intellectual and social development in the formative years of a student's life. Pupils performance lies on the expertise of a teacher. Applied to classroom setting, expertise connotes the effectiveness of the teachers to attain the objectives of the lesson, the learning activities of the teacher to ask question that develop critical thinking skill.

Caston and Jones (2004) found that interactive learning offered an opportunity to gain better understanding and insight into the preferred learning environment of the participants. According to the responses of all students, cooperative learning was the preferred method of classroom learning.

Social and emotional maturity are intertwined. Therefore, as teens emotional maturity increase their peers change as they become more vulnerable and emotionally intimate with their peers. Because acceptance by a peer group becomes so important, teens may modify their speech, dress, behavior, choices, and activities in order to become more similar to their peers.

Omas-as (2003) stated that the peer is a social group where members have common interest, social position and age. It has a unique understanding at how behave and trying to escape supervision from adult. This is when they try evade their parent's guidance as Railey (2004) considers peer group as the next most influential entity that mold human personality after the family, it is therefore vital to feel presence of the parent in their children's day to day activity in order to guide them.

Relatively Brown (2004) claimed that peer group membership can benefit students by providing friendship and by enhancing academic performance, this is where peer becomes a healthy influence to an individual.

Omas-as, Railey and Brown discussed how hefty the peers are to the student's performance. Children pick up language by echoing or imitating what they hear around them. Constant interaction with the child develops language learning. Learning while enjoying is much better than being confined in a classroom - activity environment where children often get bored and tired. Environment include not only physical stings. But psychological settings for literacy learning as well (Tharp \& Gallimore, 1992). Children are influenced by the participants present in a setting, their background experiences, their values and it is the integration of place, people, and occasion that support opportunities for learning. These individuals act as social and psychological resources that provide information and feedback through demonstrations and interactions.

Children who are English language learners experience each of these critical dimensions in the context of learning two languages, which only increases the complexity of the processes of language and literacy development. In order to become proficient in their second language, students need familiarity with the phonology, its vocabulary, its morphology and grammar (Geva, 2006). Research with second language learners has shown that oral language and literacy skills in the first language contribute to the development of those skills in the second language. For example, phonological awareness skills in the first language have been found to predict phonological awareness and word recognition in the second language (Chiappe \& Siegel, 1999; Cisero \& Royer, 1995; Durgunglu, 1998).

Deliberate approach to the selection and arrangement of materials according to specific design criteria may enhance children's uses of literacy objects and related print resources. (Beck \& Mckeown, 2007; Duke, 2000) highlight the importance of introducing children to a wide variety of books in different genres such as information books, poetry, and popular folk tales. Daily interactive book reading routine that introduces students to multiple genres, including information books, narrative, and poetry, will help them develop their English fluency.

\section{Discussion:}

Table 1:-Level of Students' Interactive Learning through Oral Presentation

\begin{tabular}{|l|c|c|c|}
\hline \multicolumn{1}{|c|}{ Oral Presentation } & MEAN & SD & Remarks \\
\hline 1. Develops my self-confidence to speak. & 3.81 & 1.02 & High Extent \\
\hline 2. Gives exposure to keep me active in the activities. & 3.74 & 0.92 & High Extent \\
\hline
\end{tabular}




\begin{tabular}{|l|c|c|c|}
\hline $\begin{array}{l}\text { 3. Develops my creativity to use the language in the } \\
\text { classroom. }\end{array}$ & 3.82 & 0.93 & High Extent \\
\hline 4. Encourages me to participate in debates. & 3.69 & 1.06 & High Extent \\
\hline 5. Enhances my ability to express myself. & 3.84 & 0.91 & High Extent \\
\hline \multicolumn{1}{|c|}{ Overall Mean } & $\mathbf{3 . 7 8}$ & \multicolumn{2}{|c|}{ High Extent } \\
\hline
\end{tabular}

The table shows the effect of oral presentation in students' behavior towards the use of the English Language. A mean of 3.81 came out in item number one which pertains to developing the self-confidence of the students in speaking followed by 3.74 mean that gives exposure to keep him active in the activities, a 3.82 mean for developing his creativity in using the language in the classroom, however a mean of 3.69 was gathered in encouraging him to participate in debates, nevertheless a 3.84 mean was gathered in enhancing his ability to express herself respectively with $1.02,0.92,0.93,1.06$, and 0.91 as standard deviation. Students' interactive learning activities in terms of oral presentations is of "high extent".

Table 2: Level of Students' Interactive Learning through Dialogues

\begin{tabular}{|l|c|c|c|}
\hline \multicolumn{1}{|c|}{ Dialogue } & MEAN & SD & Remarks \\
\hline 1. Encourage me to speak and cooperate with my partner. & 3.87 & 0.93 & High Extent \\
\hline $\begin{array}{l}\text { 2. Helps me develop my ability to express myself in a given } \\
\text { task. }\end{array}$ & 3.77 & 0.91 & High Extent \\
\hline 3. Gives me opportunity to use my speaking style. & 3.53 & 0.97 & High Extent \\
\hline 4. Uplifts my interest to participate more & 3.83 & 0.91 & High Extent \\
\hline 5. Develops my interest in speaking. & 3.76 & 1.01 & High Extent \\
\hline \multicolumn{1}{|c|}{ Overall Mean } & \multicolumn{3}{|c|}{ High Extent } \\
\hline
\end{tabular}

The table shows the effect of dialogue in encouraging the pupils to speak and cooperate with partners, develop their abilities in expressing themselves and how dialogue gives them opportunity to speak based on their style, uplifts their interest to be participative and develop their interest in speaking. The items received mean scores of 3.87, 3.77, $3.53,3.83,3.76$ respectively with standard deviations of $0.93,0.91,0.97,0.91$ and 1.01. Based on their overall mean which was 3.75 they got "Much" as remark and "high extent" as verbal interpretation.

Table 3: Level of Students' Interactive Learning through Small Group Activity

\begin{tabular}{|l|c|c|c|}
\hline \multicolumn{1}{|c|}{ Small Group Activity } & MEAN & SD & Remarks \\
\hline 1. Motivates members to participate in the activity. & 3.96 & 0.91 & High Extent \\
\hline $\begin{array}{l}\text { 2. Develops keen observation and listening to learn the script } \\
\text { and deliver it spontaneously. }\end{array}$ & 3.77 & 0.99 & High Extent \\
\hline $\begin{array}{l}\text { 3. Helps me to be responsible to learn the target lessons for the } \\
\text { day. }\end{array}$ & 4.09 & 0.88 & High Extent \\
\hline 4. Boosts my interest to be a part of the activity. & 4.01 & 0.91 & High Extent \\
\hline 5. Enables me to work with others with confidence. & 3.95 & 0.93 & High Extent \\
\hline \multicolumn{1}{|c|}{ Overall Mean } & \multicolumn{3}{c|}{ High Extent } \\
\hline
\end{tabular}

The items in this table gathered an overall mean of 3.95 and a standard deviation of 0.92 with a "much" remark and "high extent" verbal interpretation. Item number one which motivate members to participate in the activity got a mean of 3.96, 3.77 was given to item number two which is developing keen observation and listening to learn the script and deliver it spontaneously, item number three which help the respondent to be responsible to learn the target lesson for the day gathered 4.09 mean, a 4.01 mean was given for boosting the interest of the learner to be a part of the activity and enabling him to work with others with confidence got a rate of 3.95 .

Table 4: Level of Students' Interactive Learning through Role Playing

\begin{tabular}{|l|c|c|c|}
\hline \multicolumn{1}{|c|}{ Role Playing } & MEAN & SD & Remarks \\
\hline 1. Keeps me aware of my specific part to learn. & 3.74 & 1.04 & High Extent \\
\hline 2. Helps me to be alert on a given task in the play. & 3.86 & 0.95 & High Extent \\
\hline 3. Gives me sense of responsibility as a member/leader & 3.93 & 0.95 & High Extent \\
\hline 4. Lets others express themselves as a part of the play & 3.92 & 1.00 & High Extent \\
\hline 5. Helps me to keep alert for my specific role. & 3.85 & 1.00 & High Extent \\
\hline
\end{tabular}




\section{Overall Mean}

3.86

High Extent

\section{Legend:}

$\begin{array}{ll}4.51-5.00 & \text { Very Much } \\ 3.51-4.50 & \text { Much } \\ 2.51-3.50 & \text { Moderate } \\ 1.51-2.50 & \text { Little } \\ 1.00-1.50 & \text { Not at all }\end{array}$

\author{
Verbal Interpretation \\ Very High Extent \\ High Extent \\ Moderate Extent \\ Low Extent \\ Very Low Extent
}

The table shows item number 3 got the highest mean of 3.93 with 0.95 standard deviation, it displays how interactive learning activity like role playing gives a sense of responsibility as a member/leader, it is followed by item number 4 with 3.92 mean, a difference of one point from the previous one, this item shows how others express themselves as part of the play and since being part of the play requires a person of being alert it is shown to be the third with 3.86 mean and 3.85 from item number 4 . Item number 1 got the least of mean which is 3.74 , it deals with keeping the person aware of his specific part to learn. To sum up, table 6 gathers an overall mean of 3.86 with a standard deviation of 0.99 with a remark of "much" and a "high extent" of verbal interpretation.

Table 5: Level of Students’ Linguistic Environment created by Peers

\begin{tabular}{|l|c|c|c|}
\hline \multicolumn{1}{|c|}{ Peers } & MEAN & SD & Remarks \\
\hline 1. Use English in casual conversation. & 2.57 & 1.11 & Moderate Extent \\
\hline 2. Understand instructions in English in doing activities. & 2.64 & 1.07 & Moderate Extent \\
\hline $\begin{array}{l}\text { 3. Show confidence in the use of English in different } \\
\text { situations. }\end{array}$ & 2.40 & 1.11 & Low Extent \\
\hline 4. Encourage me to talk using English language. & 2.66 & 1.22 & Moderate Extent \\
\hline 5. Serve as models to encourage me to speak English. & 2.66 & 1.32 & Moderate Extent \\
\hline \multicolumn{1}{|c|}{ Overall Mean } & $\mathbf{2 . 5 9}$ & Moderate Extent \\
\hline
\end{tabular}

The table reveals the effect of peers in the oral English Performance of the learners, "moderate extent" appears to be the result as each determiner was given. Item number one which deals in the use of English in casual conversation gathers 2.57 mean with a standard deviation of 1.11 and a remark of "Sometimes", item number two which use English in giving instructions in doing activities garnered a mean of 2.64 with 1.07 standard deviation. However, showing confidence in the use of English in different situations reveals a "Rarely" remark and a mean of 2.40 which shows to be the lowest among the means given and gathered a 1.11 standard deviation. Item number 4, encouraging students to talk using English language receives a 2.66 mean as well as item number 5 which says that peer serves as model in encouraging the learner to speak English.

Table 6: Level of Students' Linguistic Environment created by Home (Family)

\begin{tabular}{|l|c|c|c|}
\hline \multicolumn{1}{|c|}{ Peers } & MEAN & SD & Remarks \\
\hline $\begin{array}{l}\text { 1. Using English in casual conversation by every member } \\
\text { of the family. }\end{array}$ & 3.07 & 1.14 & Moderate Extent \\
\hline 2. Watching English TV shows & 1.95 & 1.11 & Low Extent \\
\hline 3. Watching TV news in English & 2.70 & 1.18 & Moderate Extent \\
\hline 4. Provides gadgets in English instructions & 2.32 & 1.40 & Low Extent \\
\hline 5. Shows confidence in using English in conversation & 2.64 & 1.22 & Moderate Extent \\
\hline \multicolumn{2}{|c|}{ Overall Mean } & $\mathbf{2 . 5 4}$ & Moderate Extent \\
\hline
\end{tabular}

\section{Legend:}

4.51-5.00

$3.51-4.50$

2.51-3.50

1.51-2.50

1.00-1.50

\section{Remarks \\ Always \\ Often \\ Sometimes \\ Rarely \\ Never}

\author{
Verbal Interpretation \\ Very High Extent \\ High Extent \\ Moderate Extent \\ Low Extent \\ Very Low Extent
}


The table presents level of student's linguistic environment created by home (family). Item number 1 which use English in casual conversation by every member of the family gathered a mean of 3.07 and a standard deviation of 1.14 with a remark of "sometimes" and verbal interpretation of "moderate extent". It is followed by a 2.70 mean, watching TV news in English, 2.64 is given in item number 5 where the learner shows confidence in using the English language in conversation. Items number 2 and 4 appear to be both "low extent" in verbal interpretation with 1.95 and 2.32 mean respectively.

Table 7: Frequency and Percentage Distribution Exposure to Print Materials contributory to Linguistic Environment

\begin{tabular}{|c|c|c|c|}
\hline Print Materials & $\mathbf{F}$ & $\%$ & Remarks \\
\hline 1. Comics & 70 & 47 & Sometimes \\
\hline 2. Magazines & 122 & 81 & Always \\
\hline 3. Journals & 59 & 39 & Often \\
\hline 4. Books & 141 & 94 & Always \\
\hline 5. Readers Digest & 50 & 33 & Often \\
\hline 6. Newspapers & 126 & 84 & Always \\
\hline 7. Encyclopedia & 61 & 41 & Sometimes \\
\hline 8. Others & 58 & 39 & Often \\
\hline
\end{tabular}

The table reveals the importance of print materials in acquiring knowledge about spoken language. The more exposure a learner gets from informative reading materials the more likely he learns the language.

Table 8: Level of Students in Oral English Vocabulary Performance

\begin{tabular}{|l|c|c|c|}
\hline \multicolumn{1}{|c|}{ Vocabulary } & MEAN & SD & Remarks \\
\hline 1. Say/use varied words when performing a dialogue & 3.33 & 1.03 & Moderate Extent \\
\hline 2. Easily grasp words appropriate for the group play. & 3.24 & 1.07 & Moderate Extent \\
\hline 3. Use exact word to convey meaning. & 3.16 & 1.09 & Moderate Extent \\
\hline 4. Express him/herself freely with no hesitance & 3.37 & 1.07 & Moderate Extent \\
\hline 5. Show confidence in the use of words learned for the day. & 3.27 & 1.07 & $\begin{array}{c}\text { Moderate } \\
\text { Extent }\end{array}$ \\
\hline
\end{tabular}

The table shows item number 4 to have the highest frequency, it shows that learners are confident in speaking.

Table 9: Level of English Language in Terms of Grammar Performance

\begin{tabular}{|l|c|c|c|}
\multicolumn{1}{|c|}{ Grammar } & MEAN & SD & Remarks \\
\hline 1. Show consistency of the verbs used in writing. & 3.23 & 1.08 & Moderate Extent \\
\hline $\begin{array}{l}\text { 2. Knows how to put punctuation junction in writing } \\
\text { paragraphs. }\end{array}$ & 3.47 & 1.07 & $\begin{array}{c}\text { Moderate } \\
\text { Extent }\end{array}$ \\
\hline 3. Manifest fluency in writing short story. & 3.15 & 1.12 & $\begin{array}{c}\text { Moderate } \\
\text { Extent }\end{array}$ \\
\hline 4. Apply correct usage of words. & 3.19 & 1.13 & $\begin{array}{c}\text { Moderate } \\
\text { Extent }\end{array}$ \\
\hline 5. Aware of the usage of parts of speech. & 3.25 & 1.23 & $\begin{array}{c}\text { Moderate } \\
\text { Extent }\end{array}$ \\
\hline \multicolumn{1}{|c|}{ Overall Mean } & $\mathbf{3 . 2 6}$ & Moderate Extent
\end{tabular}

The table shows that student performance in English language in terms of grammar is of moderate extent, it is reflected on the overall mean of 3.26 and with a standard deviation of 1.13 . Item number 2 which refers to punctuation junction reflects the knowledge of the students of the language.

Table 10: Level of English Pronunciation Performance

\begin{tabular}{|c|c|c|c|}
\hline $\begin{array}{ll}\text { Students... } & \text { Pronunciation } \\
\end{array}$ & MEAN & SD & Remarks \\
\hline 1. Speak clearly at all times. & 3.46 & 1.00 & Moderate Extent \\
\hline $\begin{array}{l}\text { 2. Project voice to be heard by everybody while doing the } \\
\text { activity. }\end{array}$ & 3.40 & 0.90 & Moderate Extent \\
\hline
\end{tabular}




\begin{tabular}{|l|c|c|c|}
\hline 3. Give the correct sound needed in the role portrayed. & 3.33 & 1.03 & ModerateExtent \\
\hline 4. Vary his/her voice when necessary to avoid monotony. & 3.29 & 1.04 & ModerateExtent \\
\hline 5. Apply the correct sound of words in English & 3.26 & 1.17 & ModerateExtent \\
\hline Overall Mean & \multicolumn{2}{|c|}{$\mathbf{3 . 3 5}$} & \multicolumn{3}{c|}{ Moderate Extent } \\
\hline
\end{tabular}

Legend:

$\begin{array}{ll} & \text { Remarks } \\ 4.51-5.00 & \text { Very Much } \\ 3.51-4.50 & \text { Much } \\ 2.51-3.50 & \text { Moderate } \\ 1.51-2.50 & \text { Little } \\ 1.00-1.50 & \text { Not at All }\end{array}$

\author{
Verbal Interpretation \\ Very High Extent \\ High Extent \\ Moderate Extent \\ Low Extent \\ Very Low Extent
}

The table shows that students can speak English with correct pronunciation as appeared on item number 5 with a percentage of 1.17 with "moderate" verbal interpretation. The least as item number 2 with $90 \%$ and with a verbal interpretation of "moderate". It was followed by $1 \%$ in item number $11.03 \%$ in item number 2 and $1.04 \%$ in item number 4 which all gathered a "moderate" verbal interpretation as well.

Table 11: Relation between Interactive Learning Activities and Linguistic Environment and Students English Vocabulary Performance

\begin{tabular}{|l|c|c|c|c|}
\hline \multicolumn{1}{|c|}{ Predictor } & beta & t & Sig. & Analysis \\
\hline Interactive Learning Activities & & & & \\
\hline Oral Presentations & 0.296 & 2.180 & 0.031 & Significant \\
\hline Dialogue & -0.334 & -2.346 & 0.020 & Significant \\
\hline Small Group Activity & 0.064 & 0.435 & 0.664 & Not Significant \\
\hline Role Playing & -0.076 & -0.651 & 0.516 & Not Significant \\
\hline Linguistic Environment & & & & Not Significant \\
\hline Peers & .004 & 0.038 & 0.969 & Significant \\
\hline Home (Family) & -.285 & -2.701 & 0.008 & Not Significant \\
\hline Print Materials & .038 & 0.436 & 0.663 & \\
\hline Dependent Variable Vocabulary & \multicolumn{5}{l}{} \\
\hline
\end{tabular}

$\begin{array}{ll}\text { Adjusted R-Square } & =0.136 \\ \text { F Value } & =3.578 \\ \text { Sig. } & =0.000\end{array}$

The table shows that interactive learning as to oral presentations, dialogue, and linguistic environment as to home (family) predicts the student's oral English language performance in terms of vocabulary. The beta coefficient indicates that for every standard deviation unit increase in oral presentations, dialogue and home (family) there is a corresponding 0.296 standard deviation unit increase, -0.334 and -0.285 standard deviation unit decrease in vocabulary in student's oral English language performance in terms of vocabulary. The t-value of $2.180,-2.346$ and -2.701 is significant at $0.031,0.020$ and 0.008 levels, respectively.

The adjusted R-square of 0.136 indicates that $13.6 \%$ of change in vocabulary is due primarily to oral presentations, dialogue, and home (family). The F-value of 3.578 is significant at 0.000 levels.

Table 12: Relation between Interactive Learning Activities and Linguistic Environment and Students English Grammar Performance

\begin{tabular}{|l|c|c|c|c|}
\hline \multicolumn{1}{|c|}{ Predictor } & beta & t & Sig. & Analysis \\
\hline Interactive Learning Activities & & & & Not Significant \\
\hline Oral Presentations & 0.129 & 0.943 & 0.348 & Not Significant \\
\hline Dialogue & -0.205 & -1.430 & 0.155 & Not Significant \\
\hline Small Group Activity & 0.050 & 0.341 & 0.733 & Not Significant \\
\hline Role Playing & -0.094 & -0.803 & 0.423 & \\
\hline Linguistic Environment & & & & \\
\hline
\end{tabular}




\begin{tabular}{|l|c|c|c|c|}
\hline Peers & -0.002 & -0.021 & 0.983 & Not Significant \\
\hline Home (Family) & -0.343 & -3.220 & 0.002 & Significant \\
\hline Print Materials & 0.015 & 0.171 & 0.865 & Not Significant \\
\hline Dependent Variable: Grammar & \multicolumn{4}{|l}{} \\
\hline
\end{tabular}

Adjusted R-square

F Value

Sig.

$$
\begin{aligned}
& =0.122 \\
& =3.295 \\
& =0.001
\end{aligned}
$$

The table reveals as for English language performance in terms of grammar only the linguistic environment such as family made a great impact for it is the only determinant found to be significant.

Table 13: Relation between Interactive Learning Activities and Linguistic Environment and Students English Pronunciation Performance

\begin{tabular}{|l|c|c|c|c|}
\hline \multicolumn{1}{|c|}{ Predictor } & beta & t & Sig. & Analysis \\
\hline Interactive Learning Activities & & & & \\
\hline Oral Presentations & 0.227 & 1.647 & 0.102 & Not Significant \\
\hline Dialogue & -0.296 & -2.051 & 0.042 & Significant \\
\hline Small Group Activity & -0.006 & -0.042 & 0.967 & Not Significant \\
\hline Role Playing & 0.019 & 0.163 & 0.871 & Not Significant \\
\hline Linguistic Environment & & & & Not Significant \\
\hline Peers & -0.005 & -0.042 & 0.966 & Significant \\
\hline Home (Family) & -0.274 & -2.563 & 0.011 & Not Significant \\
\hline Print Materials & 0.054 & 0.602 & 0.548 & \\
\hline Dependent Variable: Pronunciation
\end{tabular}

Adjusted R-square

F Value

Sig.

$$
\begin{aligned}
& =0.111 \\
& =3.050 \\
& =0.002
\end{aligned}
$$

As shown in the table, interactive learning activities such as dialogue is relatively significant to linguistic environment such as Home (Family). The role of parents in developing the vocabulary cannot be over emphasized.

\section{Conclusion:}

The interactive learning activities and linguistic environment recorded significant relationship on English language performance in terms of vocabulary, grammar, pronunciation.

Inasmuch as interactive learning and linguistic environment registered significant relationship to the student's performance in oral English language; hence in this study the hypothesis stating that there is no significant relation between interactive learning and linguistic environment was completely rejected.

\section{Recommendations:}

Based on the findings and conclusions made, the following are recommended:

1. It is recommended that teachers continue to engage ESL students into interactive learning activities in the classroom to encourage the students in using the English language.

2. Teachers should do some modifications in interactive learning to stimulate higher participation among learners. They should be the role models of the English language speakers.

3. Teachers should provide more reading materials for the learners and feed them with words that will enrich their vocabulary.

4. Home (family) as part of the linguistic environment and considered as a big factor that influence the oral English language of the learners must provide, if not all, the available materials needed for the students language development.

5. Vocabulary, grammar and pronunciation can be learnt through constant practice; thus, the students should be made to talk during the English classes. 
6. For the administrators, keep on encouraging the teachers to speak English inside and outside the classroom to motivate their students to speak the language, or when the situation calls for it.

7. Send teachers to seminars and trainings pertaining to English language proficiency and confidence.

\section{References:}

1. Thoma (2015) English in Ethiopia

2. Elema (2015) English in Ethiopia

3. Mohammed (2015) General Problems of Sudanese Learners of English in The International University of Africa Compared to Nigerian Learners (Emphasis on Communicative Ability)

4. Madrunio et. al., (2018) Purposive Communication

5. Richards (2001) Curriculum Development in Language Teaching

6. Collier (2001) How Long? A Synthesis of Research on Academic Achieved in Second Language TESL

7. Qian (2008) Investigating the Relationship Between Vocabulary Knowledge and Academic Reading Performance: An Assessment Perspective

8. Swan (2005) Legislation by Hypothesis: The Case of Task-Based Instruction

9. Li, Zhong-guo; Song, Min-yan (2007) The Relationship between Traditional English Grammar Teaching and Communicative Language Teaching

10. Oxford International Encyclopedia (2003)

11. Byram (2002) Languages for Intercultural Communication and Education

12. Jenkins (2000) The Phonology of English as an International Language

13. Walker (2001) The Measurement of Word-of-Mouth Communication and an Investigation of Service Quality and Customer Commitment as Potential Antecedents

14. Seidlhofer (2002) Closing A Conceptual Gap: The Case for A Description Of English As A Lingua Franca

15. Railey (2004) Peer and Peer Pressure

16. Brown (2004) Peer Groups at the Threshold

17. Tharp and Gallimore (1992) Rousing Minds to Life: Teaching, Learning, and Schooling in Social Context

18. Geva (2006) Second-Language Oral Proficiency and Second-Language Literacy

19. Chiappe, P., \& Siegel, L. S. (1999). Phonological Awareness and Reading Acquisition in English and PunjabiSpeaking Canadian Children.

20. Cisero, C. A., \& Royer, J. M. (1995). The development and cross-language transfer of phonological awareness.

21. Beck \& Mckeown, 2007 Direct and Rich Vocabulary Instruction 